\title{
INOVASI SENI BATIK BLOK MALAYSIA
}

\author{
MOHD HAFIZ DRAHMAN*
}

\begin{abstract}
Abstrak
Estetika seni reka menceritakan kefahaman serta ketelitian gabungan elemen seni dan prinsip rekaan oleh seseorang pereka. Keunikannya mampu menarik minat seseorang dan boleh dijadikan sumber pendapatan dalam menjana ekonomi sesebuah keluarga. Seni tekstil Batik Malaysia telah mengalami pelbagai pembaharuan seiring dengan peredaran zaman. Inovasi dalam eksperimentasi teknik apabila berkarya merupakan kunci yang penting bagi memastikan industri kraf Negara untuk terus relevan pada masa depan.
\end{abstract}

Kata Kunci: Estetika, Tekstil, Batik, Inovasi, Pereka

\begin{abstract}
The aesthetics of an artwork reflects the designers own unique interpretation of his or her creation. Its uniqueness generates sources of income to many designers alike thus enriching the country with economic benefits as well culture. This is no exception to Malaysia's Batik where its appeal has been continuously revived to match the current trend with new fresh designs. Through innovation and experimentation in Batik craftsmanship, this industry will cast a brighter future on the nation's art heritage.
\end{abstract}

Keywords: Aesthetic, Textile, Batik, Innovation, Designer

* Pensyarah di Fakulti Teknologi Kreatif \& Warisan, Universiti Malaysia Kelantan 


\subsection{Pengenalan}

Seni reka tekstil Malaysia mempunyai keunikan dan gaya tersendiri. Semenjak 1930an, pelbagai rekacorak dan produk Batik telah direka oleh pereka tempatan yang kreatif dan inovatif. Teknik membatik yang digunapakai diwarisi dari pembatik-pembatik lama dan sentiasa dibuat penambahbaikan bagi memastikan warisan tradisi Batik tidak dilupakan.

Keistimewaan Batik terletak kepada elemen seni yang terdapat kepada permukaan kain Batik tersebut. Tidak dapat dinafikan bahawa setiap pengguna mempunyai pengalaman dan citarasa tersendiri dalam memilih fabric Batik yang diidamkan. Namun begitu, pereka Batik harus mengetahui akan citarasa pengguna dan trend terkini yang boleh diterapkan kedalam rekaan agar ianya kelihatan kontemporari. Keaslian Batik dirujuk kepada penggunaan bahan resist iaitu lilin bagi menghalang warna dari memasuki kawasan yang hendak dilindungi terkena warna atau menutup bahagian tertentu mengikut rekaan corak tersebut. Inovasi bahan dan teknik sudah mula diamalkan oleh pereka Batik tempatan bagi memastikan hasil Batik yang dikeluarkan adalah berbeza daripada yang lain. Teknik asas membatik menggunakan lilin digabungkan dengan pelbagai teknik bagi memperoleh kesan khas atau kelihatan ada tekstura.

\subsection{Latarbelakang Kajian}

\subsection{Teknik Batik blok}

Penggunaan blok tembaga dan kayu didalam pembuatan Batik merupakan salah satu media yang popular digunapakai bagi menghasilkan fabrik Batik ela dan kain Batik Sarong. Teknik ini dapat menghasilkan rekacorak yang sama dan konsisten apabila ianya di cop atas permukaan. Penghasilan blok tembaga memerlukan kemahiran pateri iaitu menyambungkan kepingan tembaga kecil bagi dijadikan blok batik berdasarkan corak yang direka. Prosesnya mengambil masa yang lama untuk disiapkan mengikut garisan corak tersebut.

\subsection{Kaedah Kajian}

Kaedah eksperimentasi menggunakan bahan selain tembaga tidak banyak digunakan oleh kalangan pembatik blok tempatan. Mereka lebih gemar menggunakan canting sebagai alat utama melukis corak Batik. Rekaan batik blok yang dahulu banyak memberi petunjuk untuk dijadikan sumber inspirasi untuk memilih bahan yang sesuai untuk dijadikan blok batik.

Sifat utamanya ialah bahan untuk membuat batik blok perlu tahan panas apabila dicelup dengan lilin. Selain itu, ia juga perlu tahan lasak agar blok dapat digunakan untuk membatik kain yang banyak. Keduadua sifat ini dijadikan panduan bagi membolehkan pereka batik membuat eksplorasi bahan yang sesuai 
bagi digunakan sebagai blok. Namun didalam eksplorasi bahan tersebut, kita boleh mencuba pelbagai bahan yang ada serta merekodkan secara sistematik bagi memperolehi keputusan untuk dijadikan rujukan.

Hasil eksplorasi bahan telah menemukan pereka dengan satu bahan yang mampu digunapakai bagi proses membuat batik blok iaitu daun jagung. lanya tidak cair apabila dicelup dengan lilin dan mudah dibentuk mengikut aliran corak batik yang direka. lanya tidak sama seperti tembaga namun boleh mengecop corak batik yang jelas seperti blok tembaga atau pun kayu. Bahan daun jagung mudah didapati dipasaran dan mampu dimiliki dengan harga yang berpatutan. Bahan sampingan yang lain seperti dawai dan pemegang digunakan bagi melengkapkan batik blok dan memastikan daun tidak terlerai apabila dicelup dengan lilin. Konsep ini menggalakan kreativiti pembatik dalam membuat batik blok yang lebih mudah. Batik blok tersebut telah mengalami inovasi dan tidak perlu hanya bergantung kepada satu-satu bahan bagi membuat fabrik batik blok.

\subsection{Keputusan dan Perbincangan}

\subsection{Prototaip Batik Blok}

Sehubungan dengan itu, beberapa prototaip batik blok telah dibuat bagi digunakan dalam produksi berskala kecil. Hasil daripada eksperimentasi tersebut, corak batik yang dicop keatas permukaan kain tersebut adalah jelas dan menyerupai kualiti corak lilin yang dicetak oleh blok tembaga. Sifat semulajadi daun jagung ini juga mampu menyerap lilin seperti span dimana membolehkan corak dicetak lebih sempurna pada permukaan kain. Rajah 1 menunjukkan rekaan fesyen batik menggunakan blok daun jagung.

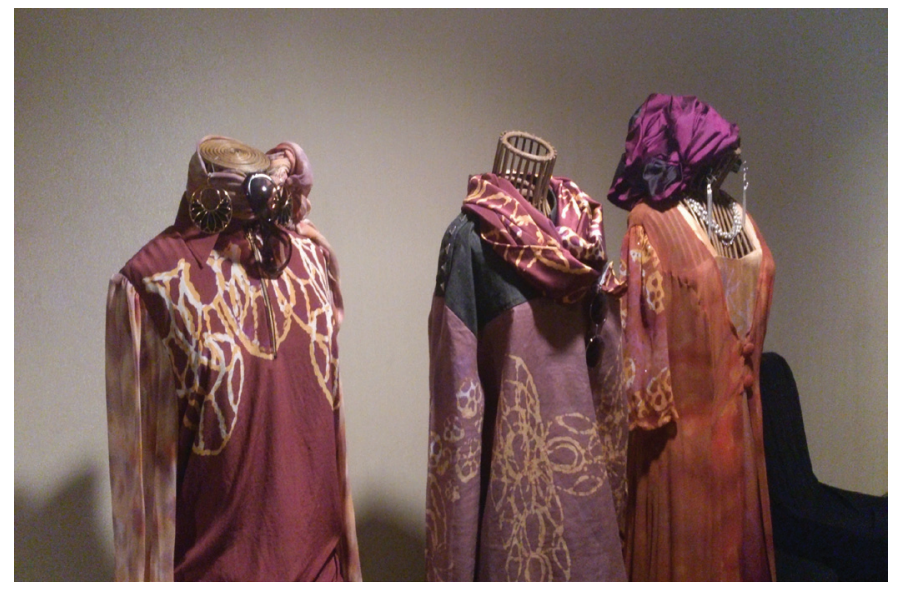

Rajah 1: Rekaan Fesyen Batik Menggunakan Blok Daun Jagung 


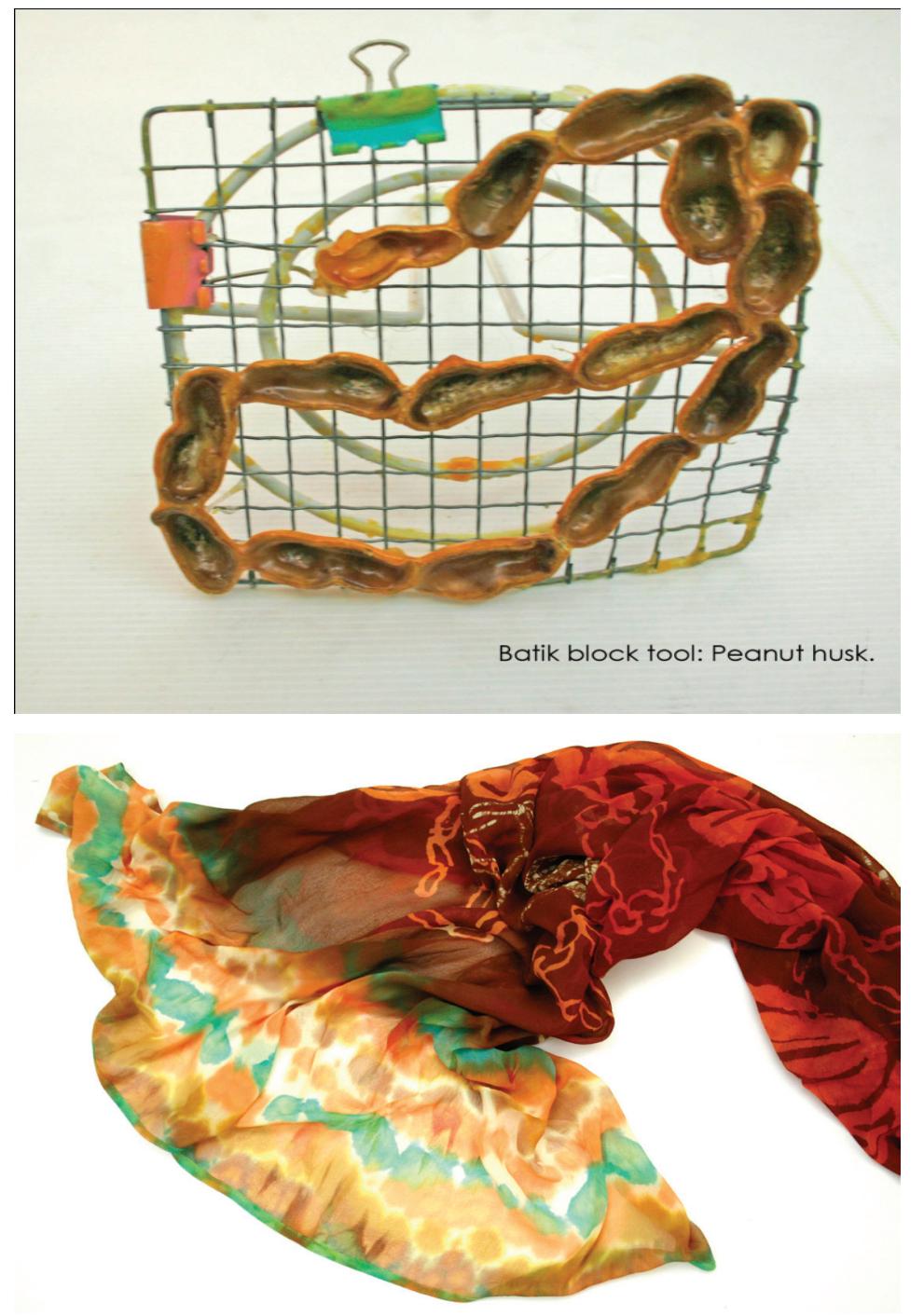

Rajah 2: Blok Batik Kulit Kacang Tanah

Rajah 3: Kain Batik Selendang Menggunakan Blok Kulit Kacang.

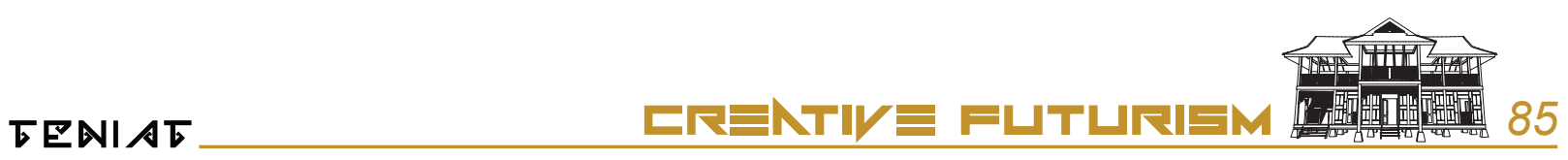




\subsection{Kesimpulan}

Inovasi di dalam bidang seni reka tekstil dan fesyen menggalakkan kreativiti menghasilkan sesuatu produk yang berkualiti. Keunikan sesuatu produk hanya akan terbentuk apabila kita memahami secara asas seni reka. Pengalaman yang terbentuk dalam proses berkarya itu akan lebih menjadikan seorang pereka pakar dalam sesuatu bidang yang diceburi. Konsep kolaborasi idea dapat menjana perkembangan proses rekaan kearah memajukan industri seni visual Negara.

\section{Rujukan}

Adline Abdul ghani, Ros Mahwati Ahmad Zakaria 2013. Tradition \& Continuity Woven and Decorated Textiled of The Malay Peninsula. Kuala Lumpur. Islamic Arts Museum Malaysia.

Arney, Sarah 1987.Malaysian Batik Creating New Traditions. Kuala Lumpur: The Malaysian Handicraft Development Corporation.

Colchester Choe, 2007. Textile Today. London: Midas Printing International.

Datuk Syed Ahmad Jamal, 2007. Crafts \& The Visual Arts The Encyclopedia of Malaysia. Kuala Lumpur: Editions Didier Millet.

Dyrenforth, Noel 2003. Modern Concepts and Techniques. United Kingdom: B T Basford.

Edwards, Clive 2009. How to Read Pattern A crash course in textile design. United Kingdom: Page One Publising Pte Ltd.

Fatimah Chik, NIL. The Batik Art of Fatimah Chik. Kuala Lumpur: Redspot Design Centre.

Fernandez, Angel 2009. Fashion Print Design from Idea to Final Print. United Kingdom: A\&C Black Publishers.

Fogg, Marnie 2006. Print in Fashion Design \& Development in Textile Fashion. United Kingdom: BT Batsford.

Haziyah hussin 2006. Motif Alam dalam Batik dan Songket Melayu. Kuala Lumpur: Dewan Bahasa dan Pustaka.

Hench, John 2008. Designing Disney Imagineering and The Art of The Show. United States of America: Disney Editions. 
Kiely, Orla 2010. Pattern. United Kingdom: Conran Octopus.

Pusat Maklumat Kraf, 1991. Motif-Motif Batik. Kuala Lumpur: Perbadanan Kemajuan Kraftangan Malaysia.

Leigh, Barbara 2000. The Changing Face of Malaysian Crafts Identity, Industry and Ingenuity. New York: Oxfors University Press.

Pepin van Roojen 2003. Batik Design. Amsterdam: The Pepin Press.

The Art Institue of Chicago, 2007.The Art of Indonesian Textiles. United States of America: Meridian Printing.

QuaChe 2007. Malaysia's Living Heritage Batik Inspirations. Kuala Lumpur: Pustaka RBS.

Syed Ahmad Jamal, 1989. Rupa dan Jiwa. Kuala Lumpur: Dewan Bahasa dan Pustaka.

Siti Zainon Ismail, 1986. Rekabentuk Kraftangan Melayu Tradisi. Kuala Lumpur: Dewan Bahasa dan Pustaka.

Storey, Joyse 1942. Textile Printing. New York: Van Nostrand Reinhold Company.

Southan, Mandy 2008. Shibori - Design and Techniques. Kuala Lumpur: Asian Edition.

Wan Hashim Wan Teh, 1996. Malay Handicraft Industries. Kuala Lumpur: Dewan Bahasa dan Pustaka.

Yayasan Tuanku Nur Zahirah, 2008. Songket Revolution. Kuala Lumpur: Yayasan Tuanku Nur Zahirah.

\section{Keratan Akhbar}

For The Love of Batik. The Star. 28 November 2013.

Blok Batik Barangan Terpakai. Kosmo. 10 Ogos 2014. 